\title{
SYNOVIAL CHONDROMATOSIS OF THE KNEE: CASE REPORT
}

Jorge Sayum Filho', Emerson Garms', Rogério Teixeira de Carvalho', Jorge Sayum², Marcelo Mitsuro Matsuda', Moisés Cohen ${ }^{3}$

\section{ABSTRACT}

The authors report the case of a patient with synovial osteochondromatosis of the knee, who had previously been a soccer player.
Keywords - Chondromatosis, Synovial; Athlete; Knee

region, diminished range of motion and diminished muscle strength.

Radiographs of the knee were requested, and these showed an image of an osteoblastic infrapatellar mass measuring $3.0 \times 3.5 \mathrm{~cm}$.

For greater elucidation of the diagnosis, magnetic resonance imaging of the left knee was requested. This showed that there was a well-delimited mass in the infrapatellar region that did not have a malignant appearance.

The patient was treated surgically, with total excision of the mass, which was sent for anatomopathological examination.

We left a splint on the malleolar thigh for analgesia, for one week, and the patient was released for physiotherapy after the splint had been removed.

Two months after the operation, the patient's range of motion in this left knee had returned to normal.

The result from the anatomopathological examination was that this was a case of synovial chondromatosis.

\section{DISCUSSION}

Osteochondromatosis is an unusual condition of unknown cause, characterized by formation of cartilage in the synovial membranes.

Synovial osteochondromatosis may be idiopathic or secondary to diseases such as osteoarthrosis, mass measuring $5.0 \mathrm{~cm} \mathrm{x} 4.0 \mathrm{~cm}$ in the infrapatellar

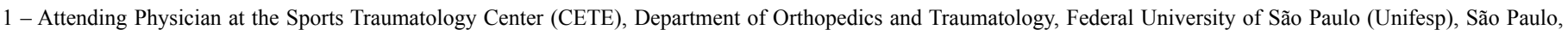
SP, Brazil.

2 - Head Physician, Department of Orthopedics and Traumatology, Assunção Hospital and Maternity Hospital (HMA), São Bernardo do Campo, SP, Brazil.

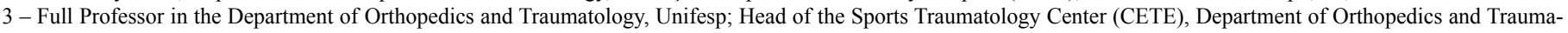
tology, Federal University of São Paulo.

Correspondence: Rua França Pinto 186, apto. 61, Vila Mariana, 04016-001 São Paulo, SP. E-mail: jorgesayumfilho@hotmail.com

Work received for publication: July 31, 2010; accepted for publication: November 3, 2010

The authors declare that there was no conflict of interest in conducting this work 
osteochondritis dissecans, chondral fractures and neuropathic arthropathy, among others ${ }^{(1-3)}$. It generally occurs in a single joint, affecting predominantly the knee, hip or elbow ${ }^{(3-5)}$.

It affects males twice as often as females, and generally occurs between the ages of 20 and 40 years ${ }^{(6,7)}$. The patients present pain, edema and limitation of their range of motion.

This is a pathological condition of progressive nature, although rare cases of spontaneous regression have been reported ${ }^{(8)}$.

The treatment is surgical and consists of excision of any intra-articular body and resection of the synovial membranes involved ${ }^{(1,9,10)}$.

The histological findings include synovial hyperplasia with foci of cartilaginous metaplasia ${ }^{(1,4,10)}$.

In this report, we described a case of synovial chondromatosis of the knee in a former soccer player that mimicked a second patella. The case was diagnosed and treated in accordance with the literature (Figures 1, 2, 3 and 4).

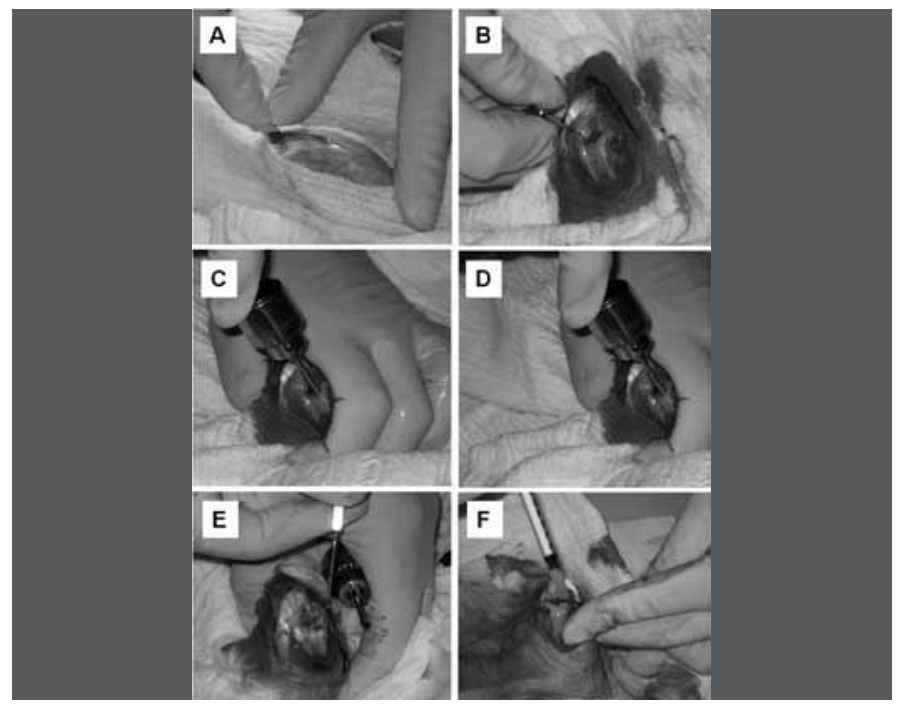

Figure 1 - Clinical appearance.

\section{REFERENCES}

1. Koyama J, Ito J, Hayashi T, Kobayashi F. Synovial chondromatosis in the temporomandibular joint complicated by displacement and calcification of the articular disk: report of two cases. AJNR Am J Neuroradiol. 2001;22(6):1203-6.

2. Kramer J, Recht M, Deely DM, Schweitzer M, Pathria MN, Gentili A, Greenway G, Resnick D. MR appearance of idiopathic synovial osteochondromatosis. J Comput Assist Tomogr. 1993;17(5):772-6.

3. Murphy FP, Dahlin DC, Sullivan R. Articular synovial chondromatosis. J. Bone Joint Surg Am. 1962;44(1):77-86.

4. Milgram JW. Synovial osteochondromatosis: a histopathological study of thirty cases. J Bone Joint Surg Am. 1977;59(6):792-801.

5. Mclvor RR, King D. Osteochondromatosis of the hip Joint. J Bone Joint Surg

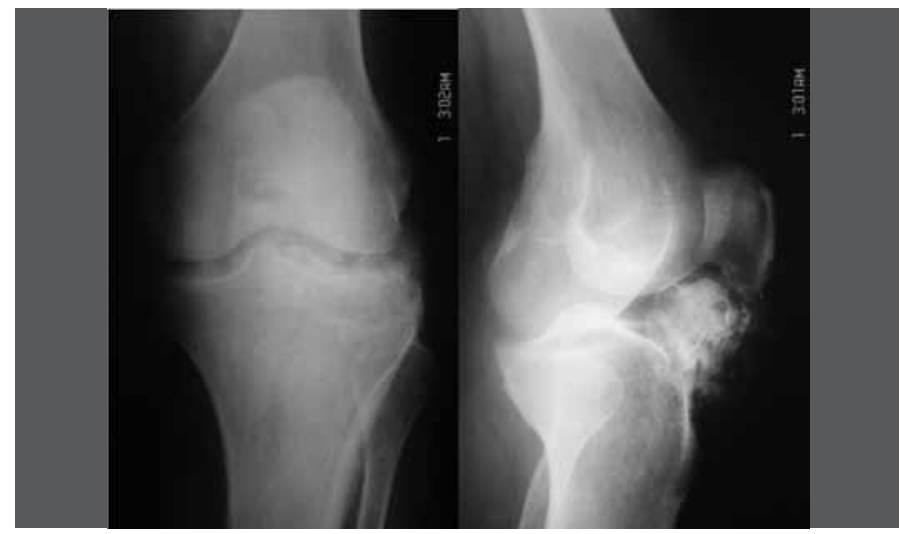

Figure 2 - Radiographs (anteroposterior and lateral views).

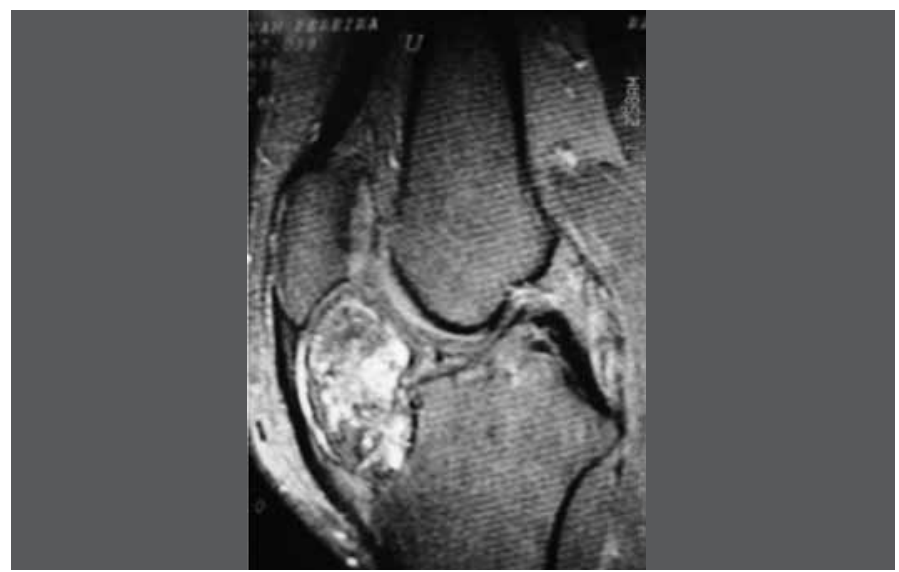

Figure 3 - Magnetic resonance imaging.

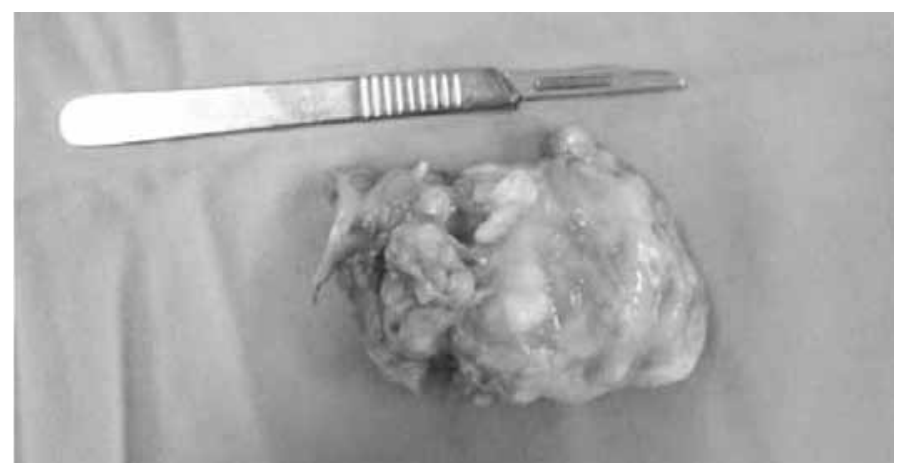

Figure 4 - Excised tumor.

Am. 1962;44(1):87-97

6. Resnick S, Niwayama G. Diagnosis of bone and joint disorders. 2nd ed. Philadelphia: Sauders; 1988.

7. Sekosky M, Lefkowitz H, Steiner I. Osteochondromatosis of the ankle. J Foot Surg. 1990;29(4):330-3.

8. Swan EF, Owens WF Jr. Synovial chondrometaplasia: a case report with spontaneous regression and a review of the literature. South Med J. 1972;65(12):1496-500.

9. Shih WJ, Ryo UY. Synovial osteochondroma of the knee in Tc-99m HMDP bone imaging. Clin Nucl Med. 1988;13(8):617-8.

10. Smith R, Hulsey JM. Bone scintigraphic demonstration of synovial chondromatosis. Clin Nucl Med. 1987;12(2):120-2. 